\title{
A case-control study on the association between bladder cancer and prior bladder calculus
}

Shiu-Dong Chung ${ }^{1,2,5}$, Ming-Chieh Tsai ${ }^{3}$, Ching-Chun Lin ${ }^{4}$ and Herng-Ching Lin ${ }^{2,5^{*}}$

\begin{abstract}
Background: Bladder calculus is associated with chronic irritation and inflammation. As there is substantial documentation that inflammation can play a direct role in carcinogenesis, to date the relationship between stone formation and bladder cancer (BC) remains unclear. This study aimed to examine the association between $\mathrm{BC}$ and prior bladder calculus using a population-based dataset.

Methods: This case-control study included 2,086 cases who had received their first-time diagnosis of BC between 2001 and 2009 and 10,430 randomly selected controls without BC. Conditional logistic regressions were employed to explore the association between BC and having been previously diagnosed with bladder calculus.

Results: Of the sampled subjects, bladder calculus was found in 71 (3.4\%) cases and 105 (1.1\%) controls. Conditional logistic regression analysis revealed that the odds ratio (OR) of having been diagnosed with bladder calculus before the index date for cases was $3.42(95 \% \mathrm{Cl}=2.48-4.72)$ when compared with controls after adjusting for monthly income, geographic region, hypertension, diabetes, coronary heart disease, and renal disease, tobacco use disorder, obesity, alcohol abuse, and schistosomiasis, bladder outlet obstruction, and urinary tract infection. We further analyzed according to sex and found that among males, the OR of having been previously diagnosed with bladder calculus for cases was $3.45(95 \% \mathrm{Cl}=2.39-4.99)$ that of controls. Among females, the OR was $3.05(95 \% \mathrm{Cl}=$ 1.53-6.08) that of controls.
\end{abstract}

Conclusions: These results add to the evidence surrounding the conflicting reports regarding the association between BC and prior bladder calculus and highlight a potential target population for bladder cancer screening.

Keyword: Bladder cancer, Bladder calculus, Case-control study

\section{Background}

Urinary calculi (UC) is a common genitourinary disorder with a worldwide lifetime incidence of $10-15 \%$ [1]. With the exception of the two World Wars, the incidence of UC has been increasing among both adults and children over the past 100 years [2-4]. Therefore, on account of the relatively high and increasing incidence rate of UC, it is important to understand what sequelae may affect the many survivors of this low-mortality condition.

Bladder cancer $(\mathrm{BC})$ is one of the most common human cancers [5]; in the United States it is fifth most commonly diagnosed cancer [6], and the eighth most common cause of death among men with cancer [7]. In

\footnotetext{
* Correspondence: henry11111@tmu.edu.tw

${ }^{2}$ School of Health Care Administration, Taipei Medical University, 250 WuHsing St, Taipei 110, Taiwan

${ }^{5}$ Sleep Research Center, Taipei Medical University Hospital, Taipei, Taiwan Full list of author information is available at the end of the article
}

the United States alone, nearly 44,690 men and 16,730 women were diagnosed with bladder cancer in 2006 [8], and the incidence has also been reported to be increasing [9]. It has been proposed that the chronic irritation and inflammation associated with UC may cause alterations in the local environment and subsequently lead to urothelial proliferation and the development of malignant neoplasms, especially transitional cell carcinoma (TCC) [10].

While the incidence of $\mathrm{BC}$ is high in most developing countries, its chief etiology is different from that of developed countries. Most cases in developing countries occur on account of infections with members of the genus Schistosoma, with $75 \%$ of all $\mathrm{BC}$ cases being squamous cell carcinomas $[8,9]$. This stands in contrast to $\mathrm{BC}$ cases in developed countries such as the United States, where TCC is reported to be the pathology

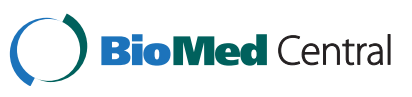


among over $90 \%$ of $\mathrm{BC}$ cases [11,12]. Therefore, it is possible that the inflammation stemming from bladder calculus may be associated with BC. Although urinary tract infections have previously been considered to be a risk factor [13-15], to date the relationship between stone formation and $\mathrm{BC}$ remains unclear $[16,17]$. Therefore, using a population-based dataset in Taiwan, this study set out to explore the association of $\mathrm{BC}$ with a previous diagnosis of bladder calculus.

\section{Methods}

\section{Database}

We obtained the data for the analyses performed in this study from the Longitudinal Health Insurance Database 2000 (LHID2000), which is derived from the Taiwan National Health Insurance (NHI) program. The LHID2000 comprises all the registration files and medical claims for the reimbursement of 1,000,000 beneficiaries, and is provided to scientists in Taiwan for research purposes. The selected beneficiaries of the LHID2000 were randomly retrieved from the year 2000 Registry of Beneficiaries ( $n=23.72$ million) of the NHI program. The Taiwan National Health Research Institute has demonstrated that the sex distribution of the LHID2000 is representative of the whole population of NHI enrollees. Numerous researchers have used this dataset to perform and publish studies in internationally peer-reviewed journals.

As the LHID2000 consists of de-identified secondary data released to the public for research purposes, this study was exempted from full review after consulting with the director of the Institutional Review Board (IRB) of Taipei Medical University.

\section{Selection of cases and controls}

We selected cases by identifying those patients $(n=$ $2,086) \geq 40$ years old who had received their first-time diagnosis of BC (ICD-9-CM codes 188 or 188.0-188.9) in ambulatory care visits or hospitalizations between January 1, 2001 and December 31, 2009. We assigned the date of their first-time diagnosis of $\mathrm{BC}$ as their index date.

For controls, we selected five subjects for each case from the remaining beneficiaries in the LHID2000. In total, 10,430 subjects were frequency-matched with cases by sex, 10-year age groups $(40-49,50-59,60-69,70-$ 79 , and $>79$ ), urbanization level of the patient's residence (5 levels, with 1 referring to the "most urbanized", and 5 the "least urbanized"), and index year and selected as controls. Controls were matched with cases in terms of urbanization level to help assure that cases and controls were reasonably similar in regard to unmeasured neighborhood socioeconomic characteristics.

\section{Exposure assessment}

We identified cases with bladder calculus by ICD-9-CM codes 594.0 (calculus in diverticulum of bladder) or 594.1 (other calculus in bladder) prior to index date. In order to ensure for high diagnostic validity, we only selected cases who had more than one bladder calculus diagnostic claim, with at least one diagnosis being made by a urologist or nephrologist.

\section{Statistical analysis}

The SAS statistical package (SAS System for Windows, Version 8.2, Cary, NC) was used to perform all the statistical analyses conducted in this study. We utilized Pearson $X^{2}$ tests to examine the distribution of sociodemographic characteristics (monthly income and geographic region (Northern, Central, Eastern, and Southern Taiwan)) and the prevalence of co-morbidities. The prevalence of comorbidities, including hypertension (ICD-9-CM codes $401 \sim 405$ ), diabetes (ICD-9-CM code 250), coronary heart disease (CHD) (ICD-9-CM codes $410 \sim 414$ ), renal disease (ICD-9-CM codes $582 \sim 586$ ), tobacco use disorder (ICD-9-CM code 305.1), obesity (ICD-9-CM code 278), alcohol abuse (ICD-9-CM codes 303), schistosomiasis (ICD-9-CM code 120), bladder outlet obstruction (ICD-9-CM code 596.0), and urinary tract infections (ICD-9-CM codes 599.0, 595.0, or 595.9) within 3 years prior to the index date were included $[8,11,16]$. Conditional logistic regressions (conditioned on sex, age group, urbanization level, and index year) were employed to explore the association between $\mathrm{BC}$ and having been previously diagnosed with bladder calculus. We further computed the odds ratio (OR) for having been previously diagnosed with bladder calculus stratified by sex. The conventional $p \leq 0.05$ was used to assess statistical significance.

\section{Results}

The mean age for the 12,516 sampled patients was 64.4 years with a standard deviation of 16 years. Table 1 shows the distribution of sociodemographic characteristics and co-morbidities between cases and controls. After matching for sex, age group, urbanization level, and index year, there was no significant difference in monthly income, geographic region, CHD, and diabetes between cases and controls. However, cases were more likely to have renal disease $(p<0.001)$, urinary tract infection $(p<0.001)$, tobacco use disorder $(p<0.001)$, but less likely to have hypertension $(p=0.018)$, than controls. No sampled subjects had ever received a diagnosis of schistosomiasis since the initiation of the NHI program.

Table 2 shows the prevalence of prior bladder calculus between cases and controls. Of 12,516 sampled subjects, $176(1.4 \%)$ had bladder calculus prior to the index date; 
Table 1 Demographic characteristics of patients with bladder cancer and comparison group patients in Taiwan, 2001-2009 ( $n=12,516)$

\begin{tabular}{|c|c|c|c|c|c|}
\hline \multirow[t]{3}{*}{ Variable } & \multirow{2}{*}{\multicolumn{2}{|c|}{$\begin{array}{c}\text { Patients with bladder cancer } \\
\qquad n=2,086\end{array}$}} & \multirow{2}{*}{\multicolumn{2}{|c|}{$\begin{array}{c}\text { Comparison patients } \\
n=10,430\end{array}$}} & \multirow[t]{3}{*}{$P$ value } \\
\hline & & & & & \\
\hline & Total No. & Column \% & Total No. & Column $\%$ & \\
\hline Age & & & & & 1.000 \\
\hline $40-49$ & 287 & 13.8 & 1,435 & 13.8 & \\
\hline $50-59$ & 377 & 18.1 & 1,885 & 18.1 & \\
\hline $60-69$ & 482 & 23.1 & 2,410 & 23.1 & \\
\hline $70-79$ & 604 & 28.9 & 3,020 & 28.9 & \\
\hline$>79$ & 336 & 16.1 & 1,680 & 16.1 & \\
\hline Sex & & & & & 1.000 \\
\hline Male & 1,332 & 63.9 & 6,660 & 63.9 & \\
\hline Female & 754 & 36.1 & 3,770 & 36.1 & \\
\hline Urbanization level & & & & & 1.000 \\
\hline 1 (most urbanized) & 707 & 33.9 & 3,535 & 33.9 & \\
\hline 2 & 568 & 27.2 & 2,840 & 27.2 & \\
\hline 3 & 276 & 13.2 & 1,380 & 13.2 & \\
\hline 4 & 290 & 13.9 & 1,450 & 13.9 & \\
\hline 5 (least urbanized) & 245 & 11.7 & 1,225 & 11.7 & \\
\hline Monthly income & & & & & 0.963 \\
\hline NT\$0-15,840 & 770 & 36.9 & 3,817 & 36.6 & \\
\hline NT\$15,841-25,000 & 903 & 43.3 & 4,537 & 43.5 & \\
\hline$\geq \mathrm{NT} \$ 25,001$ & 413 & 19.8 & 2,076 & 19.9 & \\
\hline Geographical Region & & & & & 0.911 \\
\hline Northern & 1,017 & 48.7 & 5,006 & 48.0 & \\
\hline Central & 438 & 21.0 & 2,222 & 21.3 & \\
\hline Southern & 581 & 27.9 & 2,962 & 28.4 & \\
\hline Eastern & 50 & 2.4 & 240 & 2.3 & \\
\hline Hypertension & 972 & 46.6 & 5,155 & 49.4 & 0.018 \\
\hline Renal disease & 332 & 15.9 & 73 & 7.0 & $<0.001$ \\
\hline Coronary heart disease & 455 & 21.8 & 2,445 & 23.4 & 0.107 \\
\hline Diabetes & 452 & 21.7 & 2,190 & 21.0 & 0.493 \\
\hline Schistosomiasis & 0 & - & 0 & - & - \\
\hline Bladder outlet obstruction & 35 & 1.7 & 146 & 1.4 & 0.307 \\
\hline Urinary tract infection & 724 & 34.7 & 2,931 & 28.1 & $<0.001$ \\
\hline Tobacco use disorder & 110 & 5.3 & 350 & 3.4 & $<0.001$ \\
\hline Alcohol abuse & 20 & 1.0 & 100 & 1.0 & 0.998 \\
\hline Obesity & 30 & 1.4 & 98 & 1.0 & 0.145 \\
\hline
\end{tabular}

bladder calculus was found in $71(3.4 \%)$ cases and in 105 (1.1\%) controls (chi-square value $=72.036 ; p<0.001$ ). Conditional logistic regression analysis (conditioned on age group, sex, urbanization level, and index year) revealed that the OR of having been diagnosed with bladder calculus before the index date for cases was 3.47 (95\% CI $=2.55-4.70$; $p<0.001)$ when compared with controls. After adjusting for monthly income, geographic region, hypertension, diabetes, CHD, and renal disease, tobacco use disorder, obesity, alcohol abuse, and schistosomiasis, bladder outlet obstruction, and urinary tract infection, cases were more likely to have a prior diagnosis of bladder calculus than controls ( $\mathrm{OR}=3.42 ; 95 \% \mathrm{CI}=2.48-4.72 ; p<0.001)$.

We further analyzed the OR of having been previously diagnosed with bladder calculus according to sex (Table 3). After adjusting for patient monthly income, 
Table 2 Covariate-adjusted hazard ratios for bladder calculus among the sampled patients

\begin{tabular}{|c|c|c|c|}
\hline \multirow[t]{2}{*}{ Variable } & \multicolumn{3}{|c|}{ Bladder cancer } \\
\hline & Odds ratio & $95 \% \mathrm{Cl}$ & $P$ value \\
\hline \multicolumn{4}{|l|}{ Prior bladder calculus } \\
\hline Yes & 3.42 & $2.48-4.72$ & $<0.001$ \\
\hline No (reference group) & 1.00 & & \\
\hline \multicolumn{4}{|l|}{ Monthly Income } \\
\hline NT\$1-15,840 (reference group) & 1.00 & & \\
\hline NT\$15,841-25,000 & 0.98 & $0.97-1.01$ & 0.317 \\
\hline$\geq \mathrm{NT} \$ 25,001$ & 1.01 & $0.98-1.02$ & 0.891 \\
\hline \multicolumn{4}{|l|}{ Geographic region } \\
\hline Northern (reference group) & 1.00 & & \\
\hline Central & 0.92 & $0.80-1.07$ & 0.279 \\
\hline Eastern & 0.98 & $0.86-1.11$ & 0.692 \\
\hline Southern & 0.94 & $0.68-1.31$ & 0.722 \\
\hline Hypertension & 0.80 & $0.72-0.89$ & 0.008 \\
\hline Renal disease & 2.65 & $2.28-3.08$ & $<0.001$ \\
\hline Coronary heart disease & 0.87 & $0.73-1.05$ & 0.060 \\
\hline Diabetes & 0.98 & $0.86-1.11$ & 0.742 \\
\hline Bladder outlet obstruction & 0.90 & $0.46-1.76$ & 0.751 \\
\hline Urinary tract infection & 1.23 & $1.07-1.38$ & $<0.001$ \\
\hline Tobacco use disorder & 1.46 & $1.26-1.68$ & $<0.001$ \\
\hline Alcohol abuse & 0.99 & $0.88-1.44$ & 0.983 \\
\hline Obesity & 1.03 & $0.98-1.06$ & 0.056 \\
\hline
\end{tabular}

Notes: $\mathrm{Cl}=$ confidence interval; $O R$ was calculated using Cox proportional hazard regression, stratified by sex, age, and urbanization level group.

geographic region, hypertension, diabetes, CHD, and renal disease, tobacco use disorder, obesity, alcohol abuse, and schistosomiasis, bladder outlet obstruction, and urinary tract infection, conditional logistic regression analysis revealed that among males, the OR of having been previously diagnosed with bladder calculus for cases was $3.45(95 \% \mathrm{CI}=2.39-4.99 ; p<0.001)$ that of controls. Among females, the OR of having been previously diagnosed with bladder calculus for cases was $3.05(95 \% \mathrm{CI}=1.53-6.08 ; p=0.002)$ that of controls.

\section{Discussion}

This study succeeded in identifying an association between $\mathrm{BC}$ and a prior diagnosis of bladder calculus. We found bladder cancer patients to be 3.42 times more likely than controls to have had a previous diagnosis of bladder calculus. We also found the magnitude of association to be significantly stronger among men than among women. Men with BC were 3.45 times more likely than controls to have had a previous diagnosis of bladder calculus, while women were only 3.05 times more likely.
Table 3 Covariate-adjusted hazard ratios for bladder calculus among the sampled patients, by sex

\begin{tabular}{|c|c|c|}
\hline \multirow[t]{2}{*}{ Variable } & \multicolumn{2}{|c|}{ Sex } \\
\hline & $\begin{array}{c}\text { Male } \\
\text { Bladder cancer } \\
\text { OR }(95 \% \mathrm{Cl})\end{array}$ & $\begin{array}{c}\text { Female } \\
\text { Bladder cancer } \\
\text { OR }(95 \% \mathrm{Cl})\end{array}$ \\
\hline \multicolumn{3}{|l|}{ Prior bladder calculus } \\
\hline Yes & $3.45^{* * *}(2.39-4.99)$ & $3.05^{* *}(1.53-6.08)$ \\
\hline No (reference group) & 1.00 & 1.00 \\
\hline \multicolumn{3}{|l|}{ Monthly Income } \\
\hline NT\$1-15,840 (reference group) & 1.00 & 1.00 \\
\hline NT\$15,841-25,000 & $1.21 *(1.05-1.40)$ & $1.24^{*}(1.03-1.49)$ \\
\hline$\geq \mathrm{NT} \$ 25,001$ & $1.33^{* *}(1.13-1.57)$ & $1.47^{* *}(1.12-1.92)$ \\
\hline \multicolumn{3}{|l|}{ Geographic region } \\
\hline Northern (reference group) & 1.00 & 1.00 \\
\hline Central & $0.98(0.83-1.17)$ & $0.83(0.65-1.07)$ \\
\hline Eastern & $1.06(0.90-1.23)$ & $0.86(0.70-1.07)$ \\
\hline Southern & $1.09(0.73-1.62)$ & $0.74(0.42-1.32)$ \\
\hline Hypertension & $0.88(0.77-1.01)$ & $0.69^{* * *}(0.57-0.82)$ \\
\hline Renal disease & $1.94^{* * *}(1.60-2.37)$ & $4.37^{* * *}(3.44-5.55)$ \\
\hline Coronary heart disease & $0.73^{* *}(0.63-0.86)$ & $1.03(0.83-1.28)$ \\
\hline Diabetes & $0.95(0.81-1.12)$ & $1.04(0.85-1.28)$ \\
\hline Bladder outlet obstruction & $0.90(0.45-1.79)$ & $0.45(0.02-13.73)$ \\
\hline Urinary tract infection & $1.08^{* * *}(1.04-1.11)$ & $1.53(1.47-1.58))$ \\
\hline Tobacco use disorder & $1.29^{* * *}(1.13-1.48)$ & $1.68^{* *}(1.62-1.74)$ \\
\hline Alcohol abuse & $0.95(0.83-1.09)$ & $0.99(0.95-1.03)$ \\
\hline Obesity & 1.03 (0.99-1.06) & $1.07(0.99-1.12)$ \\
\hline
\end{tabular}

Notes: OR was calculated using Cox proportional hazard regression, stratified by age and urbanization level group.

Several previous studies have been conducted on this association, but their results are in conflict. The largest case-control study performed to date set out to evaluate the role of urinary tract infection (UTI) and inflammation in the etiology of $\mathrm{BC}$ and was conducted on 2,982 bladder carcinoma patients and 5,782 population controls from ten geographic areas of the United States. They found a history of UTI to significantly increase the risk of $\mathrm{BC}$. This was stronger in individuals with three or more reported infections $(R R=2.0)$. But, irrespective of UTI, they also found a significantly increased risk of $\mathrm{BC}$ among patients with bladder stones $(\mathrm{RR}=1.8)$ [18].

There were two other studies conducted on the association between bladder calculus and $\mathrm{BC}$, but they failed to detect an association $[17,19]$. The first of these investigations was a population-based study conducted in Greater Copenhagen between 1979 and 1981. This study included 388 patients with BC and 790 controls [18]. The second study investigated the relationship between selected urinary tract and genital diseases and the risk of 
BC. In their case-control study, they analyzed that data of 364 cases of $\mathrm{BC}$ and 447 controls hospitalized for acute, nonneoplastic, nongenital tract conditions, unrelated to known or suspected risk factors for BC.

As opposed to these studies which failed to detect an association between bladder calculus and $\mathrm{BC}$, the results of this investigation support the presence of an association and are in-line with the one previous large-scale study [18]. The mechanisms underlying the associations detected in this study may involve the chronic irritation and inflammation associated with bladder calculus. One source of this inflammation is from the direct irritation of the bladder epithelial wall and another may stem from urinary tract infections which are strongly associated with urinary stones $[8,20]$.

There is substantial evidence that inflammation can play a direct role in carcinogenesis [21,22]. Both infection and irritation can cause tissue injury and result in the activation of both inflammatory cells and oxidantgenerating enzymes [22]. Chronic inflammation can induce tissue and deoxyribonucleic acid (DNA) damage by generating reactive oxygen and nitrogen species $[21,23]$.

The presence of stones and infections has been demonstrated to be important factors in the development of bladder tumors in rodents. Furthermore, these tumors are generally TCC [9], thus adding further evidence for a mechanistic connection between $\mathrm{BC}$ and bladder calculus in the absence of members of the genus Schistosoma.

This study's strengths include the use of a populationbased dataset, which enabled us to trace of all the cases of $\mathrm{BC}$ and bladder calculus during the study period. The large sample size afforded a considerable statistical advantage in detecting real differences between the two cohorts. Nevertheless, the results of this study need to be seen in the light of several limitations. The first limitation is that the diagnoses of both $\mathrm{BC}$ and bladder calculus relied on administrative claims data reported by physicians and hospitals. These data may be less accurate than diagnoses made according to standardized criteria.

Second, some patient information on factors which may have had an effect on the associations detected in this study was not available through the administrative dataset. Some of those factors include tobacco use, alcohol and betel quid consumption, dietary habits, and the body mass index. However, although we adjusted for tobacco use disorder in the regression model, this could merely mean that those subjects with such a diagnosis have undergone smoking cessation therapy. We might underestimate to use the variable as tobacco smoke because the people who receive smoking cessation therapy in clinic are only a small proportion of the smoker. One other important factor that we lacked was any exposure to aromatic amines which have been proven to contribute to the development of $\mathrm{BC}$ [11].
Third, this study may have been partially victim to a surveillance bias since patients with bladder calculus are more likely to have frequent outpatient clinic visits. But, as the first indication of $\mathrm{BC}$ is generally blood in the urine, it is unlikely that surveillance bias impacted the results of this study.

\section{Conclusion}

This investigation detected an association between $\mathrm{BC}$ and prior bladder calculus after adjusting for co-morbid medical disorders and social economic factors. These results add to the evidence surrounding the conflicting reports regarding the association between $\mathrm{BC}$ and prior bladder calculus and highlight a potential target population for bladder cancer screening.

\section{Abbreviations}

BC: Bladder cancer; OR: Odds ratio; UC: Urinary calculi; TCC: Transitional cell carcinoma; LHID2000: Longitudinal health insurance database 2000; CHD: Coronary heart disease; DNA: Deoxyribonucleic acid; UTI: Urinary tract infection.

\section{Competing interests}

The authors have no proprietary or commercial interest in any materials mentioned in this article.

\section{Authors' contributions}

Authors $\mathrm{JJ}$ and $\mathrm{HC}$ designed the study. Authors JJ, SB, CC, and HC managed the literature searches. Authors CC and HC analyzed the data. Authors JJ, SB, $\mathrm{CC}$, and $\mathrm{HC}$ wrote the draft. All authors contributed to and have approved the final manuscript.

\section{Author details}

'Division of Urology, Department of Surgery, Far Eastern Memorial Hospital, Ban Ciao, Taipei, Taiwan. ${ }^{2}$ School of Health Care Administration, Taipei Medical University, 250 Wu-Hsing St, Taipei 110, Taiwan. ${ }^{3}$ Division of Gastroenterology, Department of Internal Medicine, General Cathay Hospital, Taipei, Taiwan. ${ }^{4}$ Graduate Institute of Biomedical Informatics, College of Medical Science and Technology, Taipei Medical University, Taipei, Taiwan.

${ }^{5}$ Sleep Research Center, Taipei Medical University Hospital, Taipei, Taiwan.

Received: 25 September 2012 Accepted: 4 March 2013

Published: 15 March 2013

\section{References}

1. Long LO, Park S: Update on nephrolithiasis management. Minerva Urol Nefrol 2007, 59:317-325.

2. Goldfarb DS: Increasing prevalence of kidney stones in the United States. Kidney Int 2003, 63:1951-1952.

3. Stamatelou KK, Francis ME, Jones CA, Nyberg LM, Curhan GC: Time trends in reported prevalence of kidney stones in the United States: 1976-1994. Kidney Int 2003, 63:1817-1823.

4. López M, Hoppe B: History, epidemiology and regional diversities of urolithiasis. Pediatr Nephrol 2010, 25:49-59.

5. Burin GJ, Gibb HJ, Hill RN: Human bladder cancer: evidence for a potential irritation-induced mechanism. Food Chem Toxicol 1995, 33:785-795.

6. American Cancer Society: Cancer facts \& figures 2006. Am Cancer Soc, Atlanta (GA) 2006.

7. Jacobs BL, Lee CT, Montie JE: Bladder cancer in 2010: how far have we come? CA Cancer J Clin 2010, 60:244-272.

8. Michaud DS: Chronic inflammation and bladder cancer. Urol Oncol 2007, 25:260-268

9. Johansson SL, Cohen SM: Epidemiology and etiology of bladder cancer. Semin Surg Oncol 1997, 13:291-298. 
10. Chow WH, Lindblad P, Gridley G, Nyrén O, McLaughlin JK, Linet MS, Pennello GA, Adami HO, Fraumeni JF Jr: Risk of urinary tract cancers following kidney or ureter stones. J Natl Cancer Inst 1997, 89:1453-1457.

11. Pelucchi C, Bosetti C, Negri E, Malvezzi M, La Vecchia C: Mechanisms of disease: the epidemiology of bladder cancer. Nat Clin Pract Urol 2006, 3:327-340.

12. Silverman DT, Hartge P, Morrison AS: Epidemiology of bladder cancer. Hematol Oncol Clin North Am 1992, 6:1-30

13. Kantor AF, Hartge P, Hoover RN, Fraumeni JF Jr: Epidemiological characteristics of squamous cell carcinoma and adenocarcinoma of the bladder. Cancer Res 1988, 48:3853-3855.

14. Hartge P, Harvey EB, Linehan WM, Silverman DT, Sullivan JW, Hoover RN, Fraumeni JF Jr: Unexplained excess risk of bladder cancer in men. J Nat Cancer Inst 1990, 82:1636-1640.

15. Schottenfeld D, Fraumeni JF Jr, Silverman DT: Bladder cancer. In Cancer epidemiology and prevention. 2nd edition. Edited by Schottenfeld D, Fraumeni JF Jr. New York: Oxford University Press; 1996:1156-1179.

16. González CA, Errezola M, Izarzugaza I, López-Abente G, Escolar A, Nebot M, Riboli E: Urinary infection renal lithiasis and bladder cancer in Spain. Eur $J$ Cancer 1991, 27:498-500.

17. Kjaer SK, Knudsen JB, Sørensen BL, Møller Jensen O: The Copenhagen case-control study of bladder cancer. V. Review of the role of urinarytract infection. Acta Oncol 1989, 5:631-636.

18. Kantor AF, Hartge P, Hoover RN, Narayana AS, Sullivan JW, Fraumeni JF Jr: Urinary tract infection and risk of bladder cancer. Am J Epidemio/ 1984, 119:510-515.

19. La Vecchia C, Negri E, D'Avanzo B, Savoldelli R, Franceschi S: Genital and urinary tract diseases and bladder cancer. Cancer Res 1991, 51:629-631.

20. Thomas B, Tolley D: Concurrent urinary tract infection and stone disease: pathogenesis, diagnosis and management. Nat Clin Pract Urol 2008, 5:668-675.

21. Coussens LM, Werb Z: Inflammation and cancer. Nature 2002, 420:860-867.

22. Ohshima H, Tatemichi M, Sawa T: Chemical basis of inflammation-induced carcinogenesis. Arch Biochem Biophys 2003, 417:3-11.

23. Hussain SP, Hofseth $\sqcup$, Harris CC: Radical causes of cancer. Nat Rev Cancer 2003, 3:276-285.

doi:10.1186/1471-2407-13-117

Cite this article as: Chung et al:: A case-control study on the association between bladder cancer and prior bladder calculus. BMC Cancer 2013 13:117.

\section{Submit your next manuscript to BioMed Central and take full advantage of:}

- Convenient online submission

- Thorough peer review

- No space constraints or color figure charges

- Immediate publication on acceptance

- Inclusion in PubMed, CAS, Scopus and Google Scholar

- Research which is freely available for redistribution 